DOI: $10.12731 / 2306-1561-2013-4-11$

\title{
INCREASING THE EFFECTIVENESS OF DECISION SUPPORT SYSTEMS INFORMATION SUPPORT THROUGH THE INTEGRATION OF APPLIED INFORMATION SYSTEMS
}

\author{
Gusenitsa D.O., Yurchik P.F., Golubkova V.B.
}

\begin{abstract}
This article reviews integration aspects of decision support systems from the point of view of applied information systems and technologies. The urgency of expanding the functions of the existing systems is justified due to the increased demands from them in modern information space. The purpose of integration is defined in order to increase the efficiency of decision-making process. The key issues affecting the integration of DSS are formalized. The focus is given to the review, classification, and a brief account of current developments in the areas of integration of data management systems, services, models, and user interface. In conclusion the analysis of the properties of the integration of decision support systems and application systems is summarized with the identification of the most promising trends in this field.
\end{abstract}

Keywords: integration, integrated decision support system (IDSS), management decision-making.

\section{УДК 004.8:681.3}

\section{УВЕЛИЧЕНИЕ ЭФФЕКТИВНОСТИ РАБОТЫ СИСТЕМ ПОДДЕРЖКИ ПРИНЯТИЯ РЕШЕНИЙ С ПОМОЩЬЮ ИНТЕГРАЦИИ ПРИКЛАДНЫХ ИНФОРМАЦИОННЫХ СИСТЕМ}

Гусеница Д.О., Юрчик П.Ф., Голубкова В.Б.

\section{Аннотация}

Статья посвящена рассмотрению аспектов интеграции систем поддержки принятия решений с точки зрения прикладных информационных систем и технологий. Обоснована актуальность расширения функиий существуюших систем в связи с увеличением требований к ним в современном информачионном пространстве. Определень цели интеграции для увеличения эффективности процесса принятия решений. Формализованы ключевые вопросы, затрагивающче интеграцию СППР. Основное внимание уделено обзору, классификации и краткому изложению текущих разработок в областях интеграџии систем управления данными, сервисами, моделями и пользовательского интерфейса. В заключении подводятся итоги анализа свойств 
МАТЕРИАЛЫ ІХ МЕЖДУНАРОДНОЙ ЗАОЧНОЙ НАУЧНО-ПРАКТИЧЕСКОЙ КОНФЕРЕНЦИИ МОЛОДЫХ УЧЕНЫХ «ТЕОРИЯ И ПРАКТИКА ПРИМЕНЕНИЯ ИНФОРМАЦИОННЫХ ТЕХНОЛОГИЙ В ПРОМЫШЛЕННОСТИ И НА ТРАНСПОРТЕ», г. Москва, 12 ноября 2013 г.

интеграции СППР и прикладных систем, а также приводятся наиболее перспективные тенденции развития данной области.

Ключевые слова: интеграчия, интегрированная система поддержки принятия решений (ИСППР), управленческое решение.

\section{Введение}

Системы поддержки принятия решений (СППР) являются специфическим классом интерактивных информационных систем, созданных для упрощения выработки управленческих воздействий пользователями (экспертами, руководителями) при принятии решений в различных областях. Для этого обычная СППР в автоматизированном режиме компилирует и работает $\mathrm{c}$ неструктурированной информацией, документами, персонально вводимыми в неё данные и моделями. Это помогает пользователям системы более эффективно найти решения возникающих управленческих вопросов [1 - 7].

Вместе с тем, в современных условиях возрастают требования к системам поддержки принятия управленческих решений в информационно-аналитической деятельности [2], а именно: сокращаются сроки представления данных пользователям, увеличивается количество факторов, которые необходимо учитывать при принятии решений, предъявляются повышенные требования к оперативности управления изменениями целей, стратегий и формированию управляющих воздействий.

Ключевым вопросом в перечисленных трудностях является то, могут ли традиционные характеристики СППР быть расширены и интегрированы в новые технологии и прикладные приложения, чтобы обеспечить более прозрачное взаимодействие между пользователями, принимающими решения и самой системой для улучшения эффективности и оперативности при принятии решений.

\section{Цель интеграции СППР}

Целью интеграции СППР является повышение качества обеспечиваемой ей информационной поддержки пользователей, что достигается за счёт применения актуальных методов и алгоритмов, необходимых для интеграции СППР с прикладными информационными системами. Внедрённые методы, алгоритмы и методики интеграции ССПР должны позволять осуществлять эффективную поддержку принятия управленческих решений в автоматизированном режиме при управлении сложными процессами информационно-аналитической деятельности организаций.

$\mathrm{C}$ помощью интеграции достигается существенное расширение функциональных возможностей ССПР и эффективности принятия управленческих решений их пользователей в реальных условиях деятельности организаций путём предложения нового уровня качества управления информационно-аналитической деятельностью в рамках СППР. 


\section{Свойства интеграции СППР}

Предполагается, что интеграция - это свойства взаимосвязей какого-либо объекта (в виде моделей, сервисов, инструментов, методов, систем, подсистем) [3]. Интеграция является свойством не отдельных элементов, а их связей с другими объектами в своём окружении. Поэтому связи элементов систем и их свойства являются ключевыми понятиями для успешной интеграции систем.

В контексте СППР интеграцию можно определить как степень согласования между компонентами ИСППР. Они могут включать в себя различные виды данных, связанных функций, решения пользовательского интерфейса и других аспектов создания ИСППР.

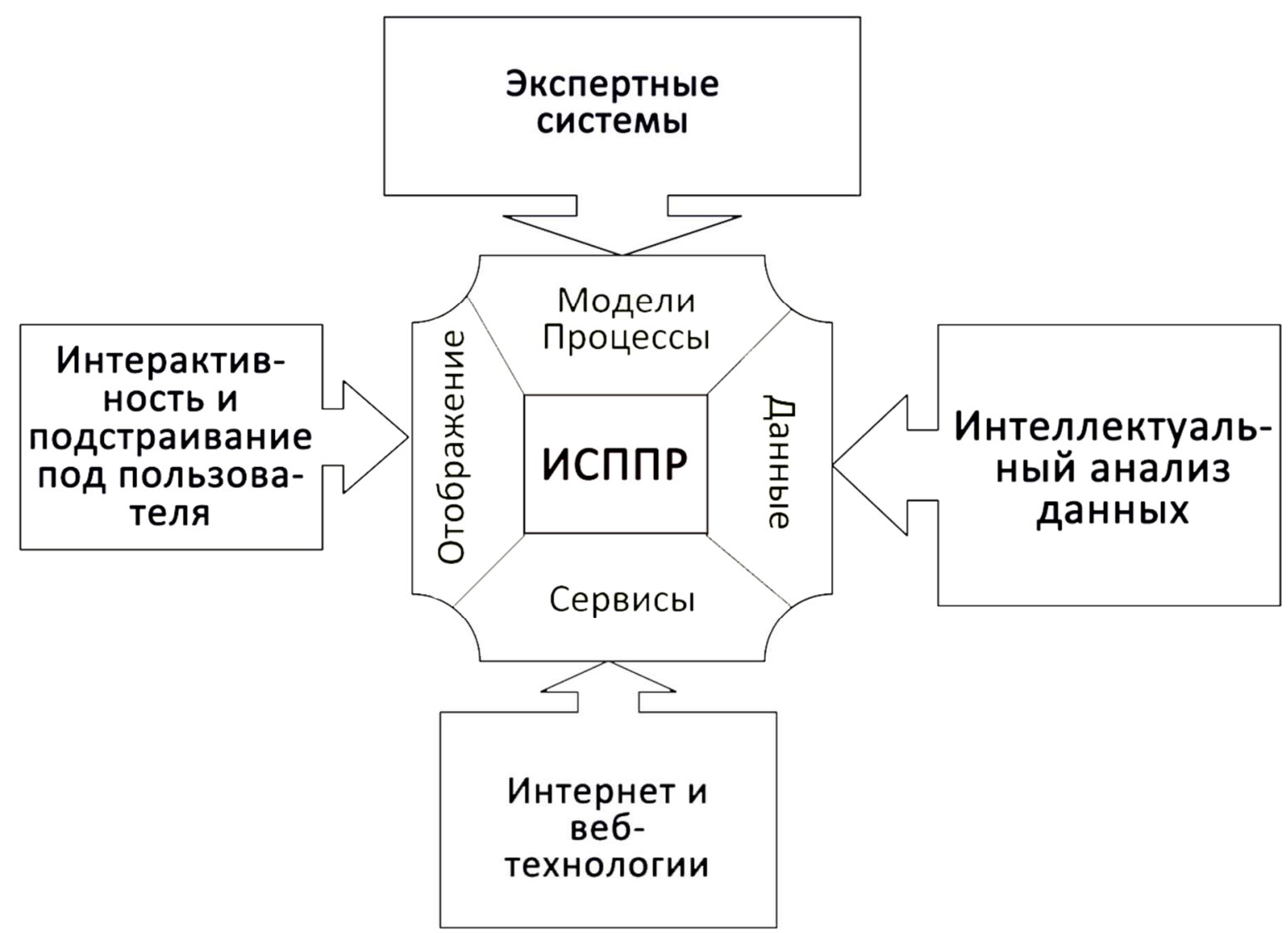

Рисунок 1 - Структура интеграции прикладных информационных приложений и технологий в ИСППР

Интеграция данных в СППР должна поддерживать работу системы над одним источником данных, несмотря на то, что в разных компонентах системы, информация обрабатывается по-разному или получается из других источников. Иначе интеграция данных между двумя компонентами системы не будет достигать своих задач, так как они будут работать с разными и не связанными потоками информации. Новые технологии управления данными, как например, хранилища данных и интеллектуальный анализ уже сейчас широко применяются в ИСППР для обработки информации и интеграции данных из различных источников [4]. Наиболее важными 
свойствами, которые должна достичь интеграция данных являются постоянство, целостность, взаимосвязанность и синхронизация.

Интеграция моделей - это процесс, в котором индивидуально созданные модели логически объединяются для создания одной большой. Подобная многомодельная интеграция успешно применяются в СППР самых различных областей от разработки программ до маркетинга и здравоохранения [4]. В области интеграции процессов требует решения важная задача создания унифицированного процесса принятия решений, который свяжет все организационные уровни среды, в которой эксплуатируется система от управленцев самого высокого уровня и менеджеров среднего звена до технического персонала.

Интеграция сервисов необходима для поддержки гибкого функционала ИСППР. В идеале все функции всех компонентов должны быть доступны по необходимости всем остальным компонентам. В таком случае интеграция данных обеспечивает работу с информацией, вопросы конвертации и хранения, а интеграция сервисов поддерживает ее контроль и передачу.

Интеграция отображения информации служит для уменьшения умственной нагрузки пользователя и применима как к отдельным компонентам и подсистемам, так и ко всей ИСППР в целом. Это достигается с помощью интеграции внешнего вида и шаблонов поведения программ, что упрощает взаимодействие пользователей с разными компонентами, потому что они разделяют одинаковый внешний вид интерфейса и шаблоны поведения. Презентация информации также представлена вопросами предоставления техническим и публичным пользователям ИСППР различной интерактивной информации, учитывающей знания и опыт пользователя в предметной области для повышения эффективности взаимодействия между пользователями и системой.

\section{Заключение}

Современное информационное пространство, в условиях которого эксплуатируются системы поддержки принятия решений, осуществляющие информационно-аналитическую деятельность, существенно повышает требования к оперативности принятия управленческих решений в условиях быстроменяющейся обстановки. Возрастает сложность задач, в рамках которых необходимо принимать решения и которые требуют огромных умственных затрат от лиц, осуществляющих управление, требуя обширных знаний и опыта в предметной области. Всё это приводит к необходимости расширения функционала систем поддержки принятия решений при сохранении быстродействия и точности выводимой информации. Вследствие этого интеграция прикладных информационных систем в системы поддержки принятия решений является наиболее фундаментальным вопросом, затрагивающим все аспекты функционирования СППР.

В перспективе важное значение следует придать вопросам универсальности и расширяемости интеграционных подходов и процессов в ИСППР, таким как гибкость и масштабируемость программных приложений системы, а также достижению 
компромисса между концепциями широкой и узкой интеграцией компонентов ИСППР. В идеале, будущие ИСППР должны обеспечивать бесшовную интеграцию между прикладными системами и внутренними компонентами.

\section{Список информационных источников}

[1] Кравчено Т.К., Середко Н.Н. Создание систем поддержки принятия решений: интеграция преимуществ отдельных подходов //Искусственный интеллект и принятие решений. - 2012. - № 1. - С.39-46.

[2] Берко Н.А. Информационная система поддержки жизненного цикла промышленной продукции / Н.А. Берко, В.Б. Голубкова, П.Ф. Юрчик // Интеграционные решения в промышленности, науке и образовании: сб. науч. тр. МАДИ. - М.: МАДИ, 2010. - С. 4-12.

[3] Карташев М.И. Проблемы принятия решений при формировании и оценивании эффективности бизнес-процессов / Брыль В.Н., Горячкин Б.С., Карташев М.И., Строганов Д.В., Якунин П.С. // Автоматизация систем поддержки управленческой деятельности: сб. науч. тр. МАДИ. - М.: МАДИ, 2011. - С. 21-28.

[4] Гусеница Д.О., Громова К.Н. Автоматизированная система на платформе pdm для поддержания работоспособности оборудования зала заседаний // Автоматизация и управление в технических системах. - 2012. - № 2; URL: auts.esrae.ru/2-39 (дата обращения: 01.11.2013).

[5] Голубкова В.Б., Юрчик П.Ф., Гусеница Д.О. Применение интегрированных систем поддержки принятия решений для предотвращения сбоёв в работе прикладных информационных систем // Автоматизация и управление в технических системах. - 2013. - № 3(5); URL: auts.esrae.ru/5-98 (дата обращения: 01.11.2013).

[6] Голубкова В.Б., Юрчик П.Ф., Гусеница Д.О. Информационная поддержка работоспособности компьютерных систем методами теории катастроф // Автоматизация и управление в технических системах. - 2013. - № 3(5); URL: auts.esrae.ru/5-99 (дата обращения: 01.11.2013).

[7] Остроух, А.В. Информационные технологии в научной и производственной деятельности / [ред. А.В. Остроух] - М: ООО "Техполиграфцентр", 2011. - 240 с. ISBN 978-5-94385-056-1. 